\title{
REVIEW OF EMPIRICAL EVIDENCE ON HOUSEHOLDS' ENERGY CHOICES, CONSUMPTION, BEHAVIORAL TENDENCIES AND PATTERNS ACROSS 32 COUNTRIES
}

\author{
FULUFHELO LICKEN MUKHADI, MACHATE MACHATE \& KHOMOTSO SEMENYA \\ University of South Africa, College of Agriculture and Environmental Sciences, Science Campus, Florida Park, \\ Republic of South Africa.
}

\begin{abstract}
Many households have restricted access to various energy types and, as a result, are faced with a daily challenge of having to make appropriate energy choices to meet their energy requirements. This paper aimed to review empirical studies on the households' energy choices and consumption patterns to establish local, regional and global trends. Our findings revealed that fuelwood, electricity, kerosene, liquified petroleum gas (LPG), charcoal, dung cakes and crop residues are the most common fuel type options available to households. Fuelwood was the most common fuel type available to the majority of the households. Our paper indicates that a significant majority of the households tend to practice energy-stacking consumption patterns. Households mostly consume fuelwood, electricity, kerosene, LPG and charcoal for cooking, lighting, water and space heating. The use of fuelwood as a major fuel by the majority of households in relation to intermediate and cleaner fuels is associated with the demographic characteristics of the households, economic status of the household, the biophysical condition of the area where the household is located and the energy supply characteristics. However, the relative importance of these factors in household energy choices varies across the globe, among regions and rural, urban and mixed settings. Our results seem to suggest that the majority of households that rely on fuelwood to meet their energy needs and requirements may relatively earn less income to afford cleaner fuels, are located closer to fuelwood resources, have larger family sizes, low level of education and possibly do not have adequate access to cleaner fuels. Our study indicates that there are weak correlations between the identified 12 factors, except in a few cases where there are moderate positive and negative and mostly significant linear relationships between some factors. The findings of this study have major implications for household energy use policies, plans and strategies.

Keywords: determinants, energy sources, factors, fuel, fuel choices, fuel stacking, fuel types, households' energy choices, household consumption patterns.
\end{abstract}

\section{INTRODUCTION}

Varieties of energy sources are vital in maintaining people's livelihoods and these include traditional energy sources (e.g. fuelwood, crop residues), intermediate energy sources (e.g. kerosene, charcoal) and cleaner energy sources (e.g. electricity, liquid petroleum gas) $[1,2]$. Of these energy types, fuelwood, electricity, kerosene, liquefied petroleum gas (LPG), charcoal, dung cakes and biogas are the most commonly consumed fuels by households in communities globally [3-5].

However, the ultimate decision to consume any or a set of these energy resources is highly linked to the demographic characteristics and economic status of the households, the biophysical conditions of the area where the household is located, the energy supply and other behavioral characteristics [6-8]. Despite a plethora of studies that demonstrated the strong and direct links between these driving forces and the ultimate energy choices of and consumption by households, there is no consensus in the literature as to which of the driving forces are most important $[4,9,10]$. 
The literature available on this topic cites many different factors as important, but all seem to concur that no factor single-handedly drives the choice and consumption of certain fuel types by households [10-12]. This could be attributed to differences in socio-economic development of the study countries and/or between some urban and rural areas [7, 13-15]. It is accepted that fuel type availability and accessibility could be the most important factor driving household energy choices in poorer communities of less economically developed countries, while fuel type reliability is a crucial driving force in poorer communities from much more economically developed countries [15-18].

Yet, the most common factors known to influence the household's energy choices have been aggregated from studies undertaken in countries at various socio-economic development stages and with somewhat different biophysical conditions [3], [4], [19]. For example, Semenya and Machete [3] reviewed 70 authoritative papers and articles from 27 different countries at varying socio-economic development levels to establish the global trends on factors that influence the selection and consumption of fuelwood energy. This has been done with little emphasis on study sites with relatively similar social, economic and energy supply characteristics, despite the importance of these aspects in energy choices.

To date, reviews on local and regional trends in factors driving households' energy choices and consumption are generally lacking in the literature. This is apart from the attempt by Akther et al. [14], who investigated the households' energy choices and their driving forces in South Asia, Northeast Asia, Africa, and Latin and Central America. Moreover, most of the studies also come short of establishing the interrelationships between the most common factors influencing household energy selection and consumption $[3,14]$, despite the importance of these in sustainable energy management plans $[4,20]$. The interrelationships between the socio-economic factors that drive household fuel choices and consumption remain unclear.

The aim of this paper is, therefore, to review the empirical studies on the household's energy choices and consumption behavioral tendencies and patterns to establish local, regional and global trends. By so doing, this paper seeks to document (1) the energy types consumed by the households, the various uses of these fuel types and the households' consumption patterns; (2) a set of factors influencing the households' energy choices; (3) the relative importance of the factors influencing the households' energy choices and (4) the interrelationships between the factors that influence household's energy choices. This was done with the view of documenting the socio-economic profile of the users of the most consumed fuel type or types.

\section{METHODS}

A total of 80 empirical studies on households' energy choices and consumption behavioral tendencies and patterns were reviewed and the retrieved information analyzed. The analysis was restricted to the 32 different countries covered by the 80 studies. The table in the Annexure summarizes the collected information. It lists the study countries, study countries' economic development and electrification levels, the most common fuels available to households and the most common statistically significant factors influencing household energy choice as specified in each reviewed literature source. As can be seen in the Annexure, of the studies analyzed, 55\% $(\mathrm{n}=44)$ were from Africa, $42 \%(\mathrm{n}=34)$ from Asia and the remaining $5 \%(\mathrm{n}=4)$ were from North and South America. These included studies undertaken at localized, national, regional and inter-regional scales. The economic development level of the study countries varied as follows: low income (12), lower middle income (13), upper middle 
income (6) and high income (01) countries. Accordingly, 50\% ( $\mathrm{n}=40), 19 \%(\mathrm{n}=15)$ and $31 \%(\mathrm{n}=25)$ of the literature items utilized were undertaken in rural, urban and mixed setting areas (urban and rural - national household surveys), respectively. It is worth noting that different studies utilized in this review seem to have adopted different methodologies for categorizing the study areas as rural or urban, as none of the studies defined what separates an urban from a rural area. Studies said to have been undertaken in mixed settings are those that undertook country-wide studies, where both rural and urban households were sampled. Data sources were randomly selected through an online search, using a content analysis method where a selected range of keywords, based on their frequency of appearance in comprehensive literature, were used as a selection criterion. Microsoft Excel 2011 software was used to analyze and determine global, regional and local scale trends on households' energy choices and consumption behavioral tendencies and patterns. Data analyses were descriptive and presented through quantitative figures, bar charts and tables.

\subsection{Fuel type options available to households}

Fuels' availability to households was calculated by extracting all the fuels cited as available for household consumption in the existing literature. The most common fuel type options available to households were determined by aggregating the observations of each fuel type cited in the reviewed paper. The top seven fuel types, as ranked by the total number of observations, were classified as the most common fuel type options available to households. The 'common' and the 'least common' fuel type options were those ranked eighth and below. It is worth mentioning that, apart from the seven most common fuels mentioned in the Annexure, 10 more fuel types were identified in the reviewed literature and were included in the subsequent calculations.

\subsection{Energy types consumed by the households}

A set of fuel types consumed by the households was determined by identifying all the energy types consumed by the households for at least one domestic purpose, while the commonly consumed fuel types were measured by ranking the number of times that each fuel type was cited as the most consumed fuel type in the reviewed paper, for either household's cooking, water heating, space heating or lighting purposes.

\subsection{Uses of the various fuel types by the households}

This was measured by counting the number of observations where a particular fuel type was cited as a carrier of choice for either cooking, water heating, space heating or lighting. It was then possible to determine and rank the fuel type mostly consumed by the households for each of the domestic purposes based on the sum.

\subsection{Factors influencing household energy choices and consumption}

The factors influencing household energy choices were aggregated by registering all the factors cited as statistically significant (5\% and $10 \%$ confidence level) in influencing the household energy choices and consumption in the reviewed literature. A total of 12 such 
factors were identified; however, only the top six ranked factors are included in the table of the Annexure. The relative importance of the factors influencing households' energy choices was measured by ranking factors in terms of the number of times a driving factor was cited as significantly influencing a household's energy consumption decisions across 80 reviewed studies. The top six ranked factors were identified and classified as the most important factors driving the global households' energy choices and consumption. These top six ranked socio-economic factors are included in the table of the Annexure.

\subsection{Interrelationships between factors influencing household's energy choices}

The interrelationships between factors were measured by applying multiple regression analysis and calculating the correlation coefficients on Microsoft Excel 2011. The relationship between two variables was considered weak when the $R$ value was below -0.2 or 0.2 , moderate when the $R$ value was between negative or positive 0.2 and 0.4 and stronger when the $R$ value was greater than negative or positive 0.7 . If the correlation coefficient of a pair of variables equals or is closer to 0.0 , it means there is no linear relationship between variables. The negative and positive signs of a correlation coefficient indicate the direction of the relationship between variables. A negative correlation coefficient implies that as the value of one variable increases, the value of other variable decreases. Positive correlation coefficient implies that the values of both variables either increase or decrease together. The output of the multiple regression analysis provided the correlation coefficient ( $R$ value) and the $p$-value for each pair of the 12 factors known to influence the household's energy choices (variables). The significance of the $p$-value was tested at $95 \%$ confidence interval. The correlation coefficient for these two variables was taken as significant when the $p$-value was $\leq 0.05$.

2.6 Correlation between the countries' level of economic development and rate of electrification

The Gross Domestic Product (GDP) comparisons using the purchasing power parity (PPP) is a good indicator of countries' economic health. This study utilized the GDP-PPP comparison to rank and classify the economic development level of the study countries. Data on the GDPPPP of the study countries was obtained from the International Monetary Fund (IMF) website. Countries with relatively higher GDP-PPP were ranked as economically healthier than those with relatively lesser GDP-PPP. The economies of the study countries were further classified as low (L), lower middle (LM), upper middle (UM) and high (H) economies based on their respective Gross National Income (GNI) per capita. Following the methodology proposed by the World Bank, countries with US $\$ \leq 10,025$ billion GNI per capita were categorized as low-income economies, and those with GNI per capita of between 1026 and 3995 were classified as lower middle-income economies. The nations whose GNI per capita was between 3996 and 12,375 were classified as upper middle-income economies, while those with $\geq 12,375$ GNI per capita were classified as high-income economies._Data on the rate of electrification across countries was downloaded from the World Bank website. The 2018 data on the countries' electrification rate and the GDP-PPP was used to calculate the correlation coefficient on Microsoft Excel 2011. The output of the multiple regression analysis provided the correlation coefficient ( $R$ value) and the $p$-value of these two variables. These outputs of the multiple regression analysis were interpreted as explained in Section 2.5. 


\section{RESULTS}

It is pointed out that all figures and tables presented in this section are based on data retrieved from the literature sources listed in the first column of the table given in the Annexure. The same table also mentions the year of publication of as well as the area (country and setting) covered by each reviewed study.

\subsection{Fuel types available for selection and consumption}

As mentioned in Section 2, the analysis revealed that 17 different fuel types are available for selection and consumption by the households globally. The number of fuel type occurrences is presented in Fig. 1 and also listed in Table 1, where they are classified as traditional (23\%), intermediate (41\%) and cleaner energy sources (35\%). As can be seen in Fig. 1, fuelwood is the most common fuel type option available to households globally (96\%), followed by electricity $(71 \%)$, kerosene (69\%), LPG (64\%), charcoal (39\%), dung cakes (30\%) and crop residues (26\%) across the globe.

Figure 2 shows the global number of observations of each fuel type in the reviewed literature broken down to each region, namely Africa, Asia and America. According to this figure, the majority of households in African, Asian and American regions have access to fuelwood, LPG, electricity, charcoal, kerosene, charcoal and dung cakes, among other fuels, while fuelwood remains the most common fuel type available for household consumption in these regions.

Table 1: Sources of energy available for household consumption globally.

\begin{tabular}{lll}
\hline Traditional energy sources & $\begin{array}{l}\text { Intermediate energy } \\
\text { sources }\end{array}$ & Cleaner energy sources \\
\hline A. Fuelwood & A. Kerosene & A. Electricity \\
B. Dung cakes & B. Charcoal & B. LPG \\
C. Non-woody plant materials & C. Coal & C. Natural gas \\
D. Crop residues & D. Candle & D. Battery \\
& E. Paraffin & E. Bio-gas \\
& F. Diesel & F. Solar \\
\hline
\end{tabular}

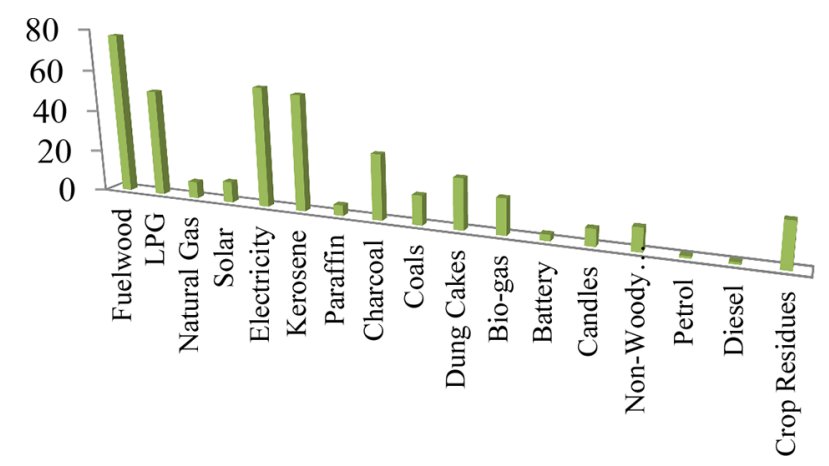

Figure 1: Fuel type options available to households globally. 


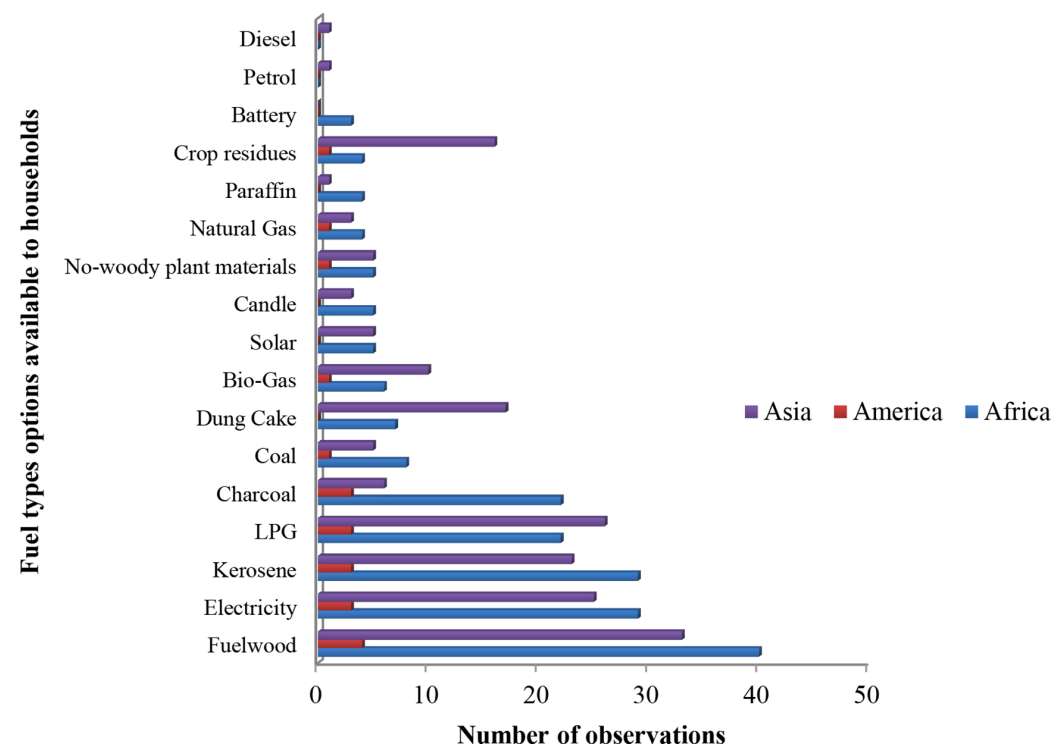

Figure 2: Fuel type options available to households per region.

Figure 3 shows the global number of occurrences of each fuel type in the reviewed literature broken down to each type of household setting, namely urban, rural or mixed. According to this figure, fuelwood, electricity, kerosene, LPG, charcoal, dung cakes and crop residues remain the most common fuel type options available to households in rural, urban and mixed settings, while fuelwood is again the most common fuel type available for household consumption in either rural, urban or mixed settings.

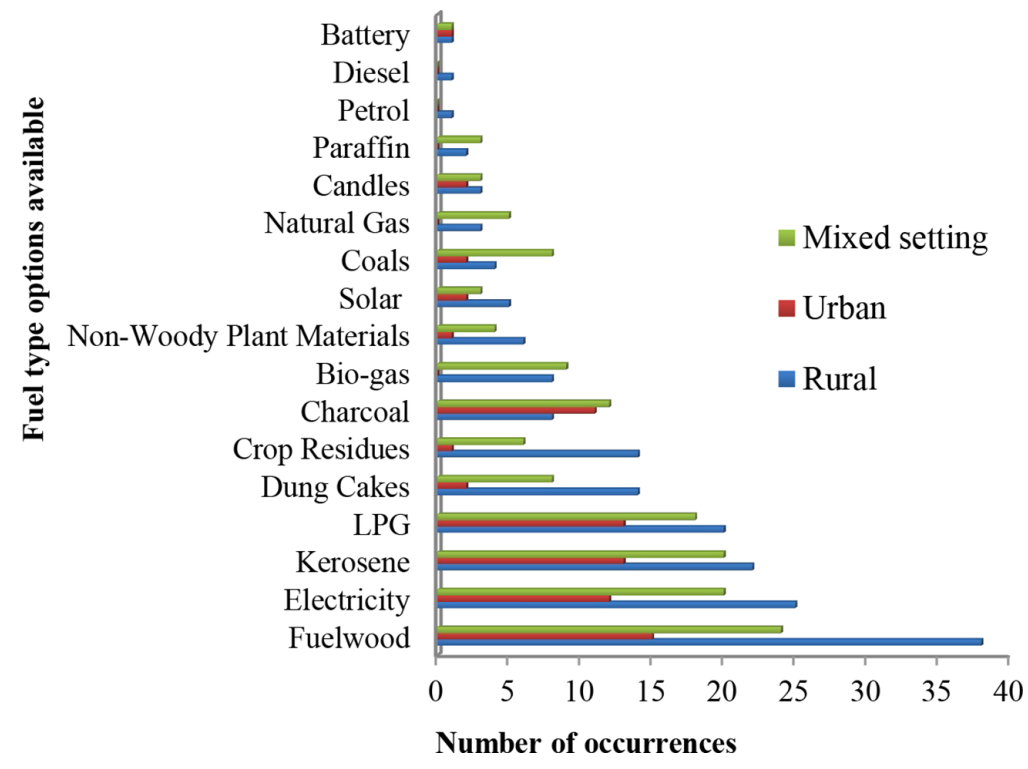

Figure 3: Fuel types options available to households per location setting. 
Table 2: Uses of different energy sources by the households.

\begin{tabular}{lllll}
\hline Fuel type & Cooking & Heating (space) & Heating (water) & Lighting \\
\hline Fuelwood & $\sqrt{ }$ & $\sqrt{ }$ & $\sqrt{ }$ & $\sqrt{ }$ \\
LPG & $\sqrt{ }$ & $\sqrt{ }$ & $\sqrt{ }$ & $\sqrt{ }$ \\
Kerosene & $\sqrt{ }$ & $\sqrt{ }$ & $\sqrt{ }$ & $\sqrt{ }$ \\
Charcoal & $\sqrt{ }$ & $\sqrt{ }$ & $\sqrt{ }$ & $\mathrm{X}$ \\
Electricity & $\sqrt{ }$ & $\sqrt{ }$ & $\sqrt{ }$ & $\sqrt{ }$ \\
Dung cakes & $\sqrt{ }$ & $\sqrt{ }$ & $\sqrt{ }$ & $\mathrm{X}$ \\
Crop residue & $\mathrm{X}$ & $\sqrt{ }$ & $\sqrt{ }$ & $\mathrm{X}$ \\
Paraffin & $\mathrm{X}$ & $\mathrm{X}$ & $\mathrm{X}$ & $\sqrt{ }$ \\
Solar & $\mathrm{X}$ & $\sqrt{ }$ & $\sqrt{ }$ & $\sqrt{ }$ \\
\hline
\end{tabular}

\subsection{Energy uses and consumption strategies}

The descriptive analysis of the previous section showed that fuelwood, electricity, kerosene, LPG and charcoal are the most consumed fuels globally. Based on data retrieved from the literature sources listed in the Annexure, it was possible to produce Table 2 and Fig. 4, which indicate that these energy carriers are preferred for various domestic purposes including cooking, water heating, space heating and lighting. Figure 4, in particular, provides the frequency of each fuel use corresponding to each domestic energy purpose. It is seen in that figure that fuelwood is preferred by the majority of the households for cooking, water heating, space heating purposes and it is an alternative source of energy for lighting, while electricity is the preferred energy carrier for lighting within the global households, followed by kerosene.

As indicated in Table 3, it was also observed that a significant majority of the households tend to practice energy-stacking consumption patterns where more than one fuel is

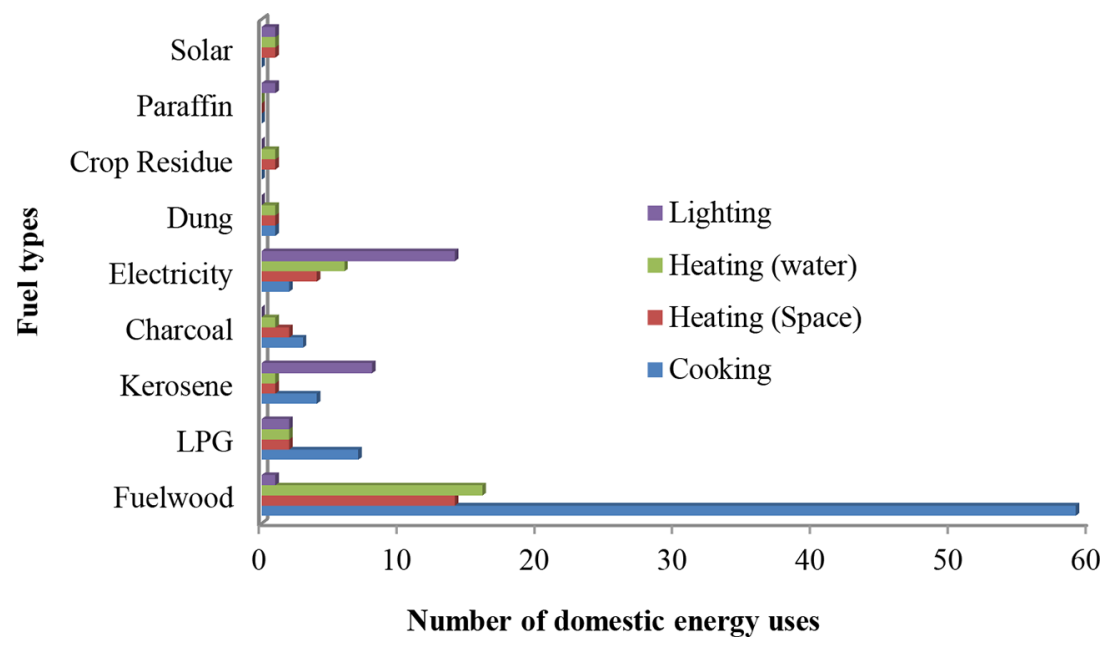

Figure 4: Fuel types and their domestic uses in the households globally. 
Table 3: Households' energy consumption patterns globally.

\begin{tabular}{lc}
\hline & Household energy consumption patterns \\
Utilization method & Rating (\%) \\
\hline A. Energy stacking & 87.5 \\
B. Single energy & 12.5 \\
\hline
\end{tabular}

consumed. Results plotted in Figs 5 and 6 for Africa and Asia, respectively, indicate that households in these regions mostly use fuelwood for cooking, space heating and water heating, while electricity and kerosene are preferred for lighting households. This is also clearly seen in Fig. 7, where the frequency of fuel use for cooking alone has been plotted.

The frequency of fuel use for cooking per household setting (urban, rural or mixed) is described by the bar charts of Fig. 8. These findings indicate that fuelwood is the most favored energy carrier for cooking by households in rural areas relative to households in urban areas

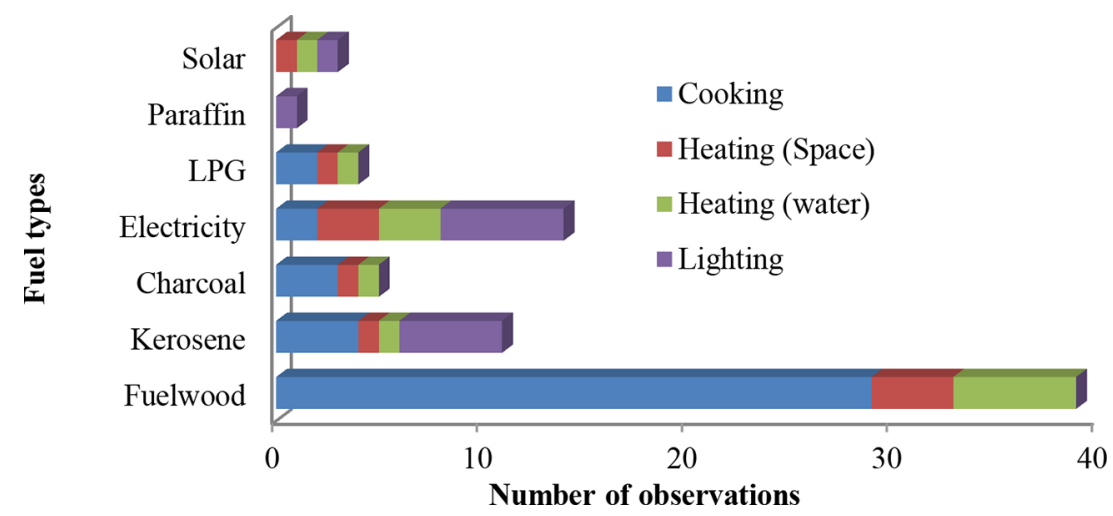

Figure 5: Household energy consumption patterns and their uses - Africa.

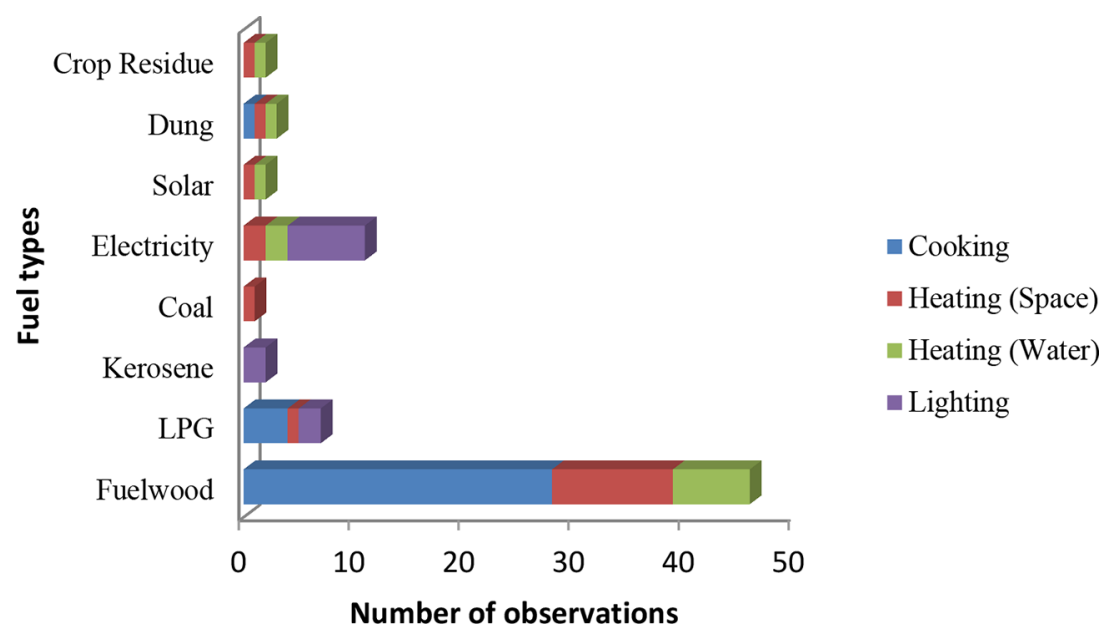

Figure 6: Energy consumptions patterns and their uses - Asia. 


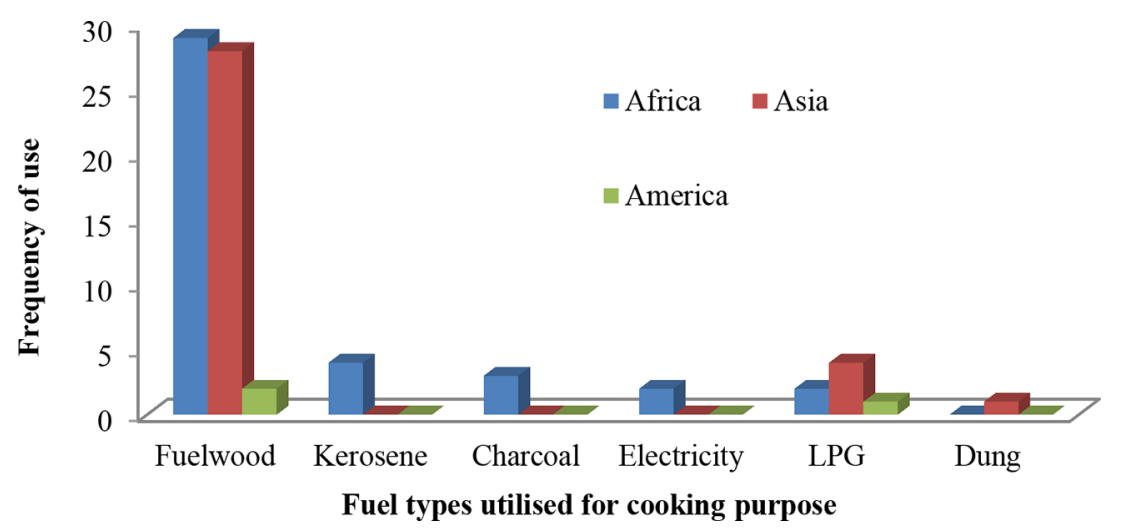

Figure 7: Fuel types utilized for cooking in the households (by region).

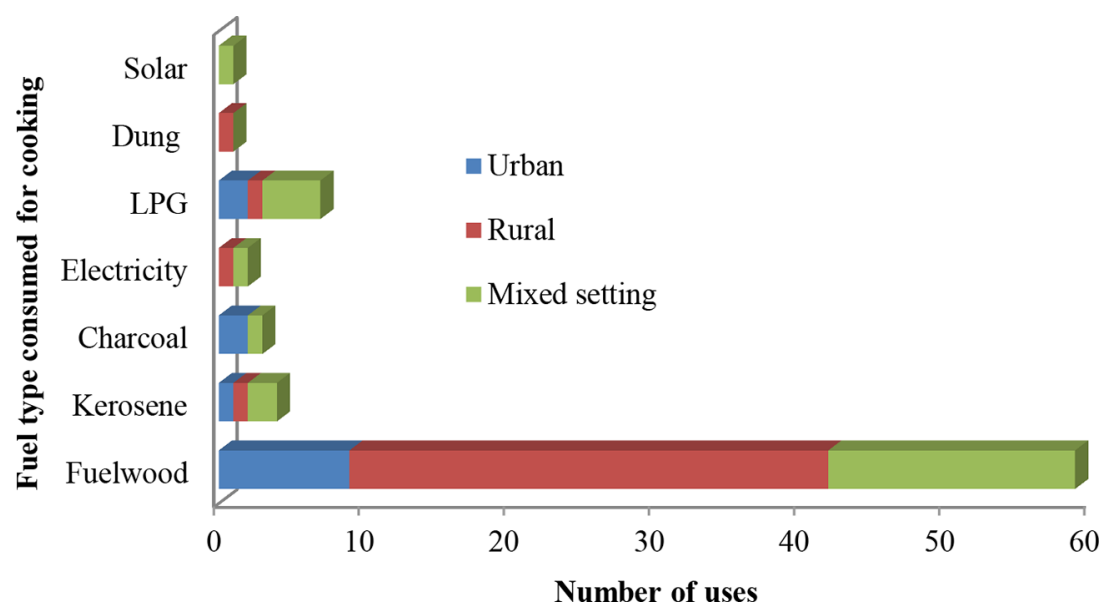

Figure 8: Fuel types utilized for cooking in the households (by setting).

and those in mixed settings, while reliance on fuelwood for cooking is much less in households located in urban areas than those in rural and mixed settings.

\subsection{Relative importance of the factors that influence the households' energy choices}

The classification of the 12 identified factors is presented in Table 4 and the number of their occurrences in Fig. 9. It is seen in Table 4 that these factors are distributed across four broad categories, namely, demographic characteristics of the households, economic status of the household, the biophysical condition of the area where the household is located and the energy supply characteristics. However, the relative importance of these factors in influencing household energy choices varies across the globe and among regions and rural, urban and mixed settings. The data from the reviewed studies, as plotted in Fig. 9, demonstrate that household wealth status $(87 \%)$ is the most important factor driving the global household's energy choices and consumption, followed by fuel availability and accessibility (57\%), household size (52\%), fuel cost/affordability (51\%), education level of the household head $(50 \%)$ and the household location (42\%). 
Table 4: Categories of factors that influence the household's energy choices.

\begin{tabular}{llll}
\hline Economic & Fuel supply & Demographic & Biophysical condition \\
\hline $\begin{array}{l}\text { A. House- } \\
\text { hold wealth } \\
\text { status }\end{array}$ & $\begin{array}{l}\text { A. Fuel availability } \\
\text { and accessibility }\end{array}$ & A. Household size & A. Household location \\
& B. Fuel cost & $\begin{array}{l}\text { B. Household head educa- } \\
\text { tional level }\end{array}$ & $\begin{array}{l}\text { B. Household dwell- } \\
\text { ing type }\end{array}$ \\
& $\begin{array}{l}\text { C. Fuel type im- } \\
\text { pact or benefit }\end{array}$ & $\begin{array}{l}\text { C. Household head gender } \\
\end{array}$ & $\begin{array}{l}\text { D. Household head age } \\
\text { E. Household head marital } \\
\text { status }\end{array}$ \\
& & F. Household culture & \\
& &
\end{tabular}

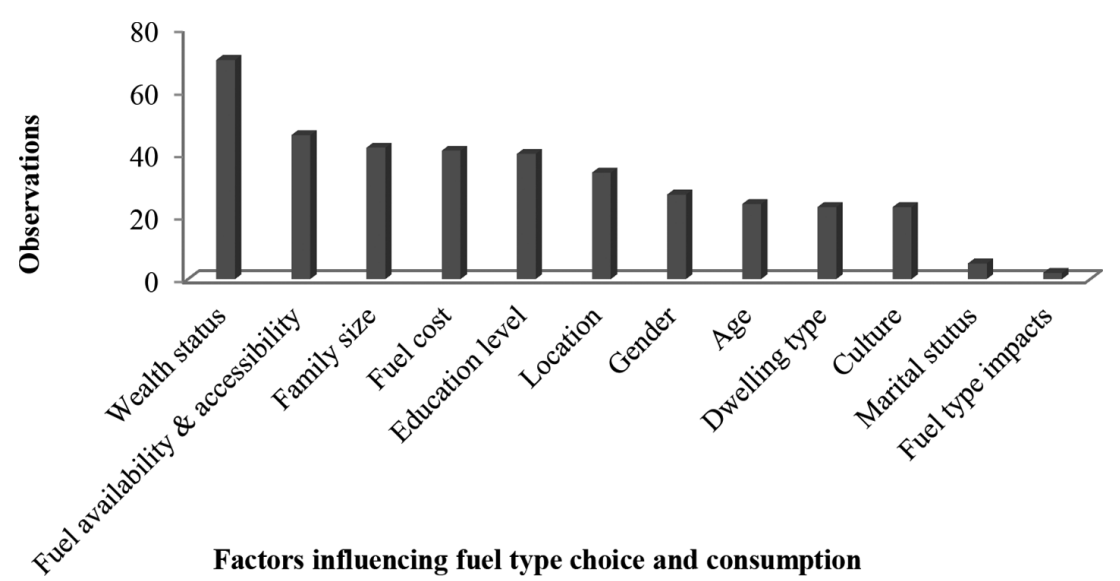

Figure 9: Factors influencing the fuel type choice and consumption (globally).

Figure 10 shows again the number of observations for each factor broken down to the contributions from the three regions: Africa, Asia and America. Expressed in terms of percentages for each region, the results show that the household's wealth status $(84 \%)$, education level (61\%), family size (54\%), fuel cost (50\%), fuel availability and accessibility (47\%) and location $(40 \%)$ are largely important in influencing the energy choices by households located in the Africa region; while within the Asian households, the households' wealth status (85\%), fuel availability and accessibility (64\%), education level (50\%), family size (50\%), fuel cost (44\%) and location (44\%) are the critical driving forces.

The number of observations for each factor influencing the fuel type choice and consumption is plotted in Fig. 11 for each location setting: urban, rural and mixed. In terms of percentages per setting, this chart reveals that factors such as household wealth status (87\%), fuel availability and accessibility (60\%), family size (47\%), fuel cost (45\%), education level $(40 \%)$ and location $(37 \%)$ are the major determinants of energy choices in households located 


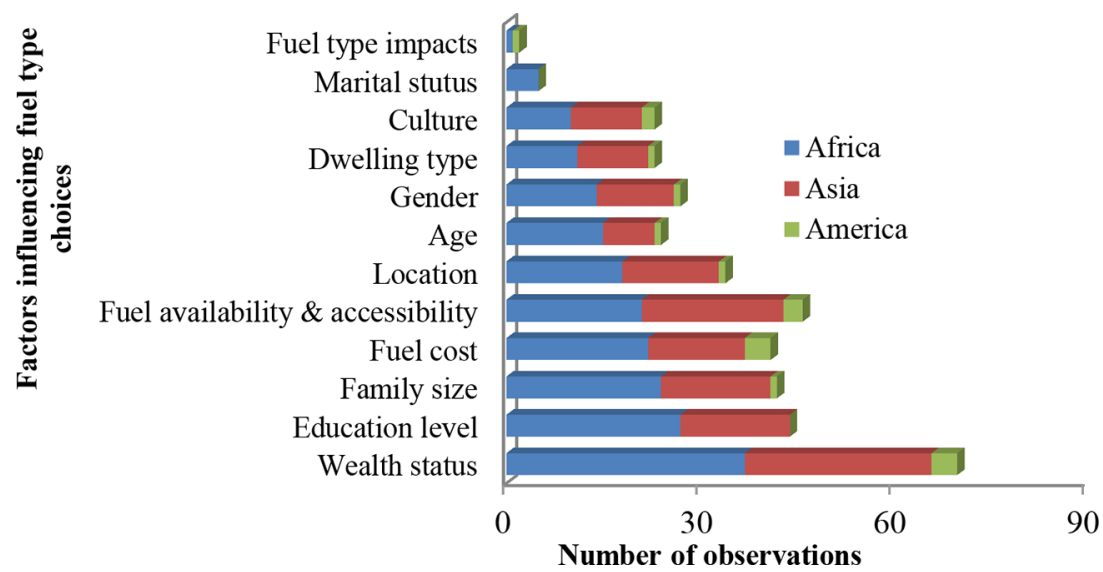

Figure 10: Factors influencing the fuel type choice and consumption (regionally).

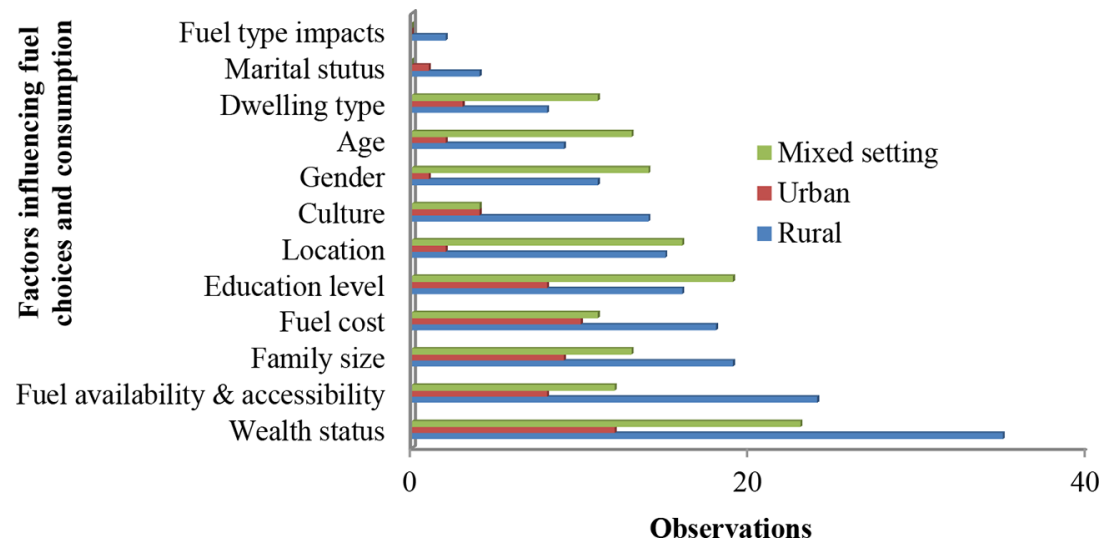

Figure 11: Factors influencing the fuel type choice and consumption (local).

in rural areas. The roles of households' wealth status, family size, fuel cost, culture (35\%) and fuel availability and accessibility seem to be more pronounced in rural areas than in urban areas and mixed settings. The household's wealth status (92\%), educational level (76\%), location (64\%), gender (56\%), family size (52\%), age (52\%) and dwelling type (44\%) play a major role in households located in mixed settings.

\subsection{Relationship between factors that influence the households' energy choice}

The results of the multiple regression analysis are presented in Table 5, which provides the correlation coefficient $R$ and the $p$-value (strength of the relationship) for each pair of variables. These results indicate that there are generally weak correlations between the identified 12 factors, except for a few cases where there are moderate positive and negative and mostly significant linear relationships between two factors. In particular, positive, moderate and significant linear relationships between household location and wealth status, household head's education level and household wealth status, and household head education level and 


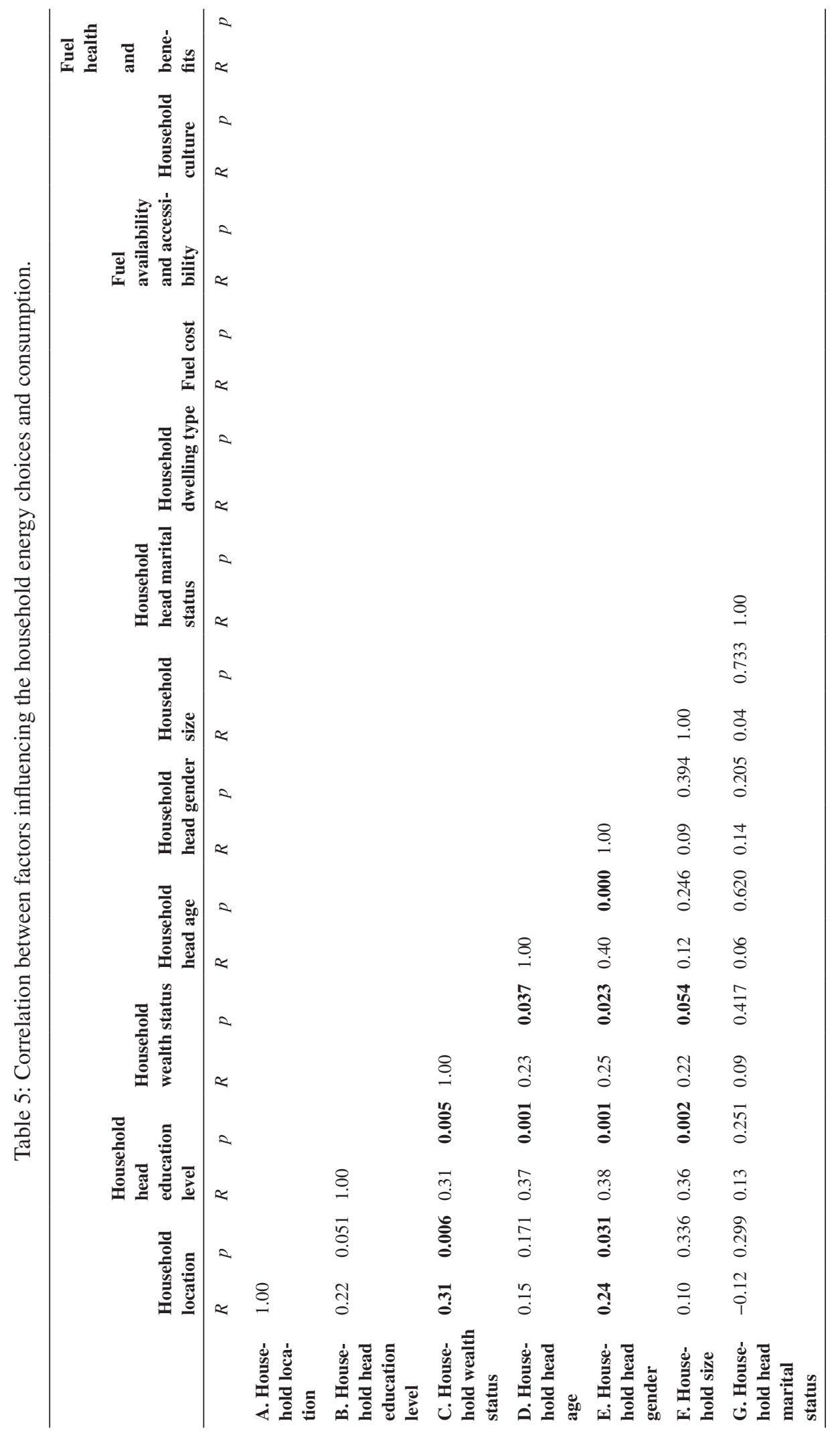




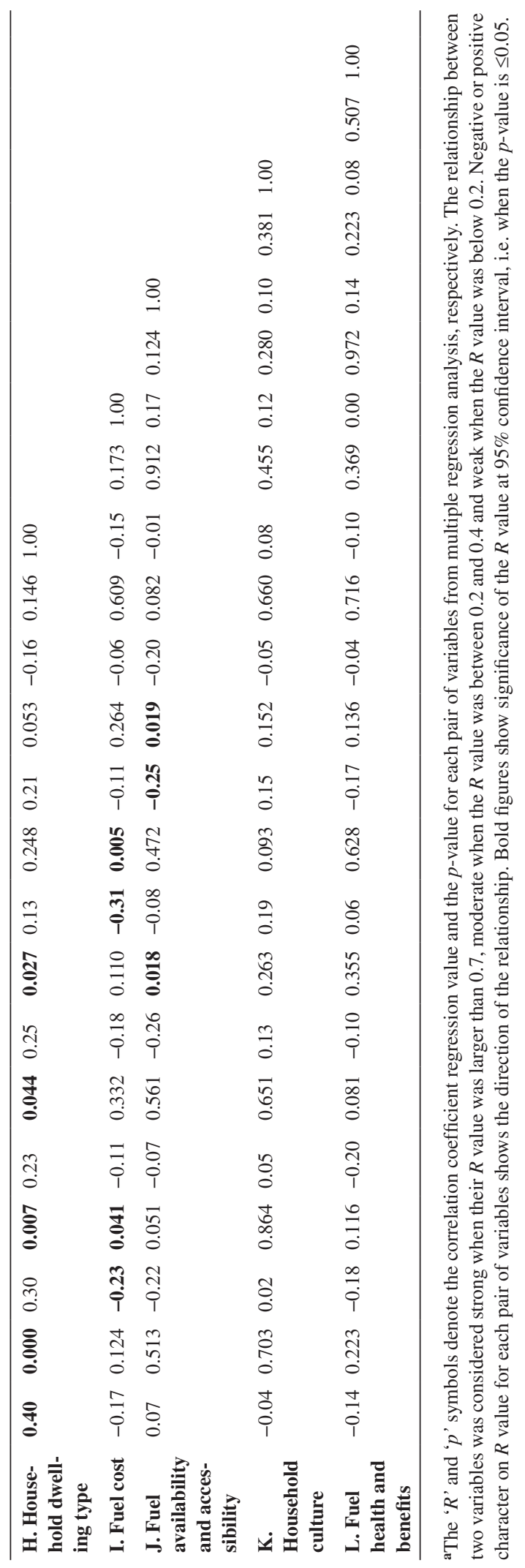


household size were found. A negative, moderate and significant linear relationship was also found between fuel cost and household head gender, and household size and fuel availability and accessibility.

3.5 Correlation between the countries' level of economic development and rate of electrification

The results of the multiple regression analysis are presented in Fig. 12, which provides the correlation coefficient $R$ and the $p$-value of the relationship between the countries' economic development and rate of electrification. As seen in Fig. 12, multiple regression analysis revealed that there is a positive and moderate linear relationship between the country's economic development level and the rate of electrification. The respective correlation coefficient is significant at 0.03 . Countries with relatively higher GDP-PPP ( $>1322$ trillion), including China, USA, India, Indonesia, Brazil, Mexico and Thailand, have relatively higher electrification rate, while those nations that recorded lower GDP-PPP had lower electrification level. However, there have been some instances where relatively higher ranked nations had lower electrification rate (e.g. India $-95 \%$ and Nigeria $-57 \%$ ) relative to lowly ranked nations (e.g. Timor-Leste $-86 \%$ and Bhutan $-100 \%$ ).

Lower-income economies also exhibited lower electrification rates. Approximately $<50 \%$ of the population in poorer countries such as Burundi, Burkina Faso, Malawi, Ethiopia, Tanzania, Lesotho, Uganda, Zimbabwe, Zambia and Malawi have access to electricity. However, other low-income economies like Tajikistan (99\%), Nepal (94\%) and Timor-Leste (86\%) have relatively higher electrification rate when compared to fellow economies. The electrification rate for lower middle-income economies is $\geq 57 \%$ and as high as $99 \%$, except for Angola which has an electrification rate of $43 \%$. The entire population (100\%) of the upper middle-income economies, apart from Botswana (65\%) and Namibia (54\%), have access to

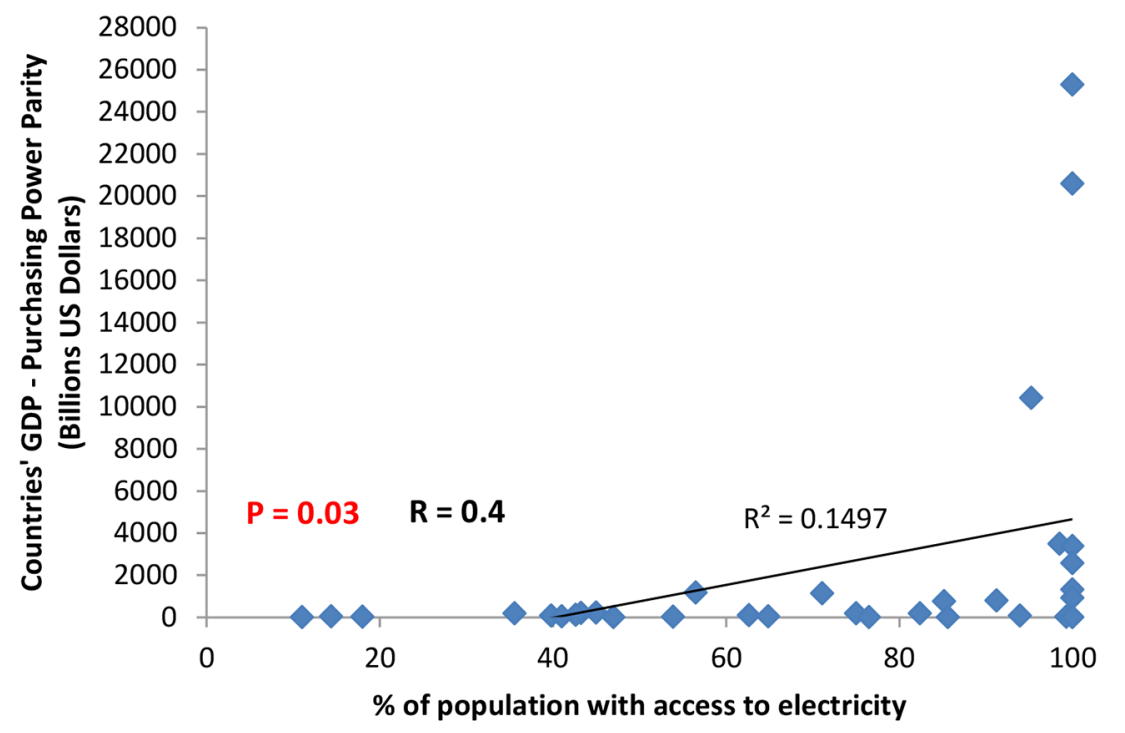

Figure 12: Correlation between the countries' level of economic development and \% of population with access to electricity. 
electricity. USA was the only nation classified as high-income economy, and similar to most upper middle-income economies, has a $100 \%$ electrification rate.

\subsection{Result summary}

This paper aimed to review the empirical studies on the households' energy choices and consumption behavioral tendencies and patterns to establish regional and global trends. The main findings of this study reveal that global households in communities have access to 17 fuels. Fuelwood, a traditional fuel, was the most readily available fuel type for the majority of the households and this was well ahead of clean (electricity and LPG), intermediate (charcoal, kerosene) and other traditional dirty fuels (dung cakes and crop residues). The paper revealed that the majority of the households do practice multiple fuel stacking techniques, where dirty, intermediate and clean fuels are consumed simultaneously. It was found that fuelwood, electricity, kerosene, LPG, charcoal, dung cakes and crop residues were the fuels most utilized by the households for cooking, water heating, space heating and lighting. The present study also revealed that a vast majority of global households rely on fuelwood for cooking, water heating and space heating purposes. Results show that the use of fuelwood as a major source by the majority of households in relation to intermediate and cleaner fuels is largely associated with the household wealth status, fuel availability and accessibility, family size, fuel cost, household head's education level, household location, household head's age, household head's marital status, household culture and dwelling type. However, the relative importance of these factors in influencing household energy choices varied across the globe, among regions and rural, urban and mixed settings. Yet, the fuel choices of the vast majority of households were largely driven by their wealth status. The present study indicated that there are weak correlations between the identified 12 factors except for a few cases where there are moderate positive and negative and mostly significant linear relationships between two factors. Results also showed that higher income economies have higher electrification rate, while poorer nations have lower electrification level.

\section{CONCLUSIONS}

The findings from this review study reveal that the largest proportions of the households have access to fuelwood, electricity, LPG, kerosene, charcoal, dung cakes and crop residues and these were the fuels most utilized by the households for cooking, water heating, space heating and lighting through multiple fuel stacking patterns. The utilization of cleaner and traditional fuels concurrently could be linked to the inability of one fuel to meet all the households' energy needs and requirements. However, the vast majority of households rely on fuelwood for cooking, water heating and space heating purposes. The results show that the use of fuelwood as a major source by the majority of households in relation to intermediate and cleaner fuels is associated with the 12 socio-economic factors. However, the relative importance of these factors in influencing household energy choices varied across the globe, among regions and rural, urban and mixed settings. Yet, the factors (drivers) with the largest impact in households' energy choices largely remain common across the globe, regions and local levels, except in mixed settings where household age, gender and dwelling type play a much central role. Thus, the reliance on fuelwood is largely associated with the household's wealth status, location, size, educational level, fuel cost and fuel availability and accessibility. These factors also happen to be the poverty-defining variables, while the fuel choices of the vast majority of households were largely driven by the households' wealth status and other socio-economic 
variables. Results also revealed that higher-income economies have higher electrification rate, while poorer nations have lower electrification level as measured by the percentage of populations with access to electricity.

The presented results seem to suggest that the majority of the households globally that rely on fuelwood to meet their energy needs and requirements may earn relatively less income to afford cleaner fuels, located closer to fuelwood resources, have larger family sizes, low level of education and possible do not have access to cleaner fuels amongst other characteristics. This could also be associated with the fact that fuelwood is readily available and accessible to households from nearby woodlands, affordable, efficient and does not require specialized installation and appliances, while intermediate and clean fuels are often relatively inaccessible and expensive and are thus restricted to affluent households. The variation in the relative importance of the factors influencing household energy choices across the globe, among regions and rural, urban and mixed settings implies that scale-based specific sets of determinants should be prioritized in attempts to understand the households' energy choices and consumption behavioral tendencies and patterns.

The findings of this study have major implications for household energy use policies including future energy plans and strategies. Households that have access to other fuels and yet still primarily rely on fuelwood could be encouraged, through awareness raising programs, to adopt cleaner fuels to lessen their high dependence on fuelwood. Where a complete switch from fuelwood to cleaner fuels is not economically feasible, major efforts should be geared toward improving the fuelwood use efficiency in kitchens and increasing the supply of fuelwood resources to reduce the overexploitation of fuelwood resources. Reducing or subsidizing the prices of alternative fuels as part of a broader poverty reduction program would also empower economically marginalized households to afford fuelwood substitutes. The use of fuelwood substitutes could also be enhanced by investing in vigorous programs aimed at increasing the supply and access to cleaner fuels.

\section{REFERENCES}

[1] Ateba, B.B., Prinsloo, J.J. \& Fourie, E., The impact of energy fuel choice determinants on sustainable energy consumption of selected South African households. Journal of Energy in Southern Africa, 29(3), pp. 51-65, 2018. https://doi.org/10.17159/24133051/2018/v29i3a4714

[2] Meijaard, E., Abram, N.K., Wells, J.A., Pellier, A.S., Ancrenaz, M., Gaveau, D.L.A., et al., People's perceptions about the importance of forests on Borneo. PLoS One, 8(9), 2013.

[3] Semenya, K. \& Machete, F., Factors that influence firewood use among electrified Bapedi households of Senwabarwana Villages, South Africa. African Journal of Science, Technology, Innovation and Development, 11(6), pp. 719-729, 2019. https://doi. org/10.1080/20421338.2019.1572336

[4] Makonese, T., Ifegbesan, A.P. \& Rampedi, I.T., Household cooking fuel use patterns and determinants across southern Africa: Evidence from the demographic and health survey data. Energy \& Environment, 29(1), pp. 29-48, 2018. https://doi. org/10.1177/0958305x17739475

[5] Kowsari, R. \& Zerriffi, H., Three dimensional energy profile : A conceptual framework for assessing household energy use. Energy Policy, 39(12), pp. 7505-7517, 2011. http:// dx.doi.org/10.1016/j.enpol.2011.06.030 
[6] Etim, N.A., Thompson, D. \& Etefia, C.E., Influence of socio economic variables on domestic cooking energy choices of rural poor households. American Journal of Energy Science, 5(1), pp. 1-6, 2018.

[7] Bisu, D.Y., Kuhe, A. \& Iortyer, H.A., Urban household cooking energy choice : an example of Bauchi metropolis, Nigeria. Energy, Sustainability and Society, 6, pp. 1-12, 2016. http://dx.doi.org/10.1186/s13705-016-0080-1

[8] Malla, S. \& Timilsina, G.R., Household Cooking Fuel Choice and Adoption of improved Cookstoves in Developing Countries: A Review. Policy Research Work Papers, World Bank, Washington DC, 2014.

[9] Rahut, D.B., Mottaleb, K.A. \& Ali, A., Household energy consumption and its determinants in Timor-Leste. Asian Development Review, 34(1), pp. 167-197, 2017. https:// doi.org/10.1162/adev_a_00085

[10] Nyankone, B.O., Factors influencing choice of sources for domestic energy used in households in Thuti Sub-Location, Othaya. Journal of Energy Technologies and Policy, 6(7), pp. 1-9, 2016.

[11] Niyongabo, P. \& Makonese, T., Analysis of household energy uses in Mubuga informal settlement, Gitega, Burundi. Journal of Human Ecology, 57, pp. 38-46, 2017. https://doi.org/10.1080/09709274.2017.1311653

[12] Jan, G., et al., An ethnobotanical survey on fuel wood and timber plant species of Kaghan Valley, Khyber Pakhtoonkhwa Province, Pakistan. African Journal of Biotechnology, 10(82), paper 19075-83, 2011. https://doi.org/10.5897/ajb10.980

[13] Danlami, A.H., An analysis of the determinants of households' energy choice: A search for conceptual framework. International Journal of Energy Economics and Policy, 5(1), pp. 197-205, 2015.

[14] Akther, S., Miah, D. \& Koike, M., Driving forces for fuelwood choice of households in developing countries: Environmental implications for Bangladesh. International Journal of Biodiversity Science, Ecosystem Services \& Management, 6(1-2), pp. 35-42, 2010. https://doi.org/10.1080/21513732.2010.505011

[15] Ouedraogo, N.S., Energy futures modelling for African countries: LEAP model application, WIDER Working Paper 2017/56. 2017. https://www.wider.unu.edu/ sites/ default/files/wp2017-56.pdf

[16] Díez, H.E. \& Pérez, J.F., Physicochemical characterization of representative firewood species used for cooking in some Colombian regions. International Journal of Chemical Engineering, 2017, pp. 1-13, 2017. https://doi.org/10.1155/2017/4531686

[17] Chen, Q., Yang, H., Liu, T. \& Zhang, L., Household biomass energy choice and its policy implications on improving rural livelihoods in Sichuan, China. Energy Policy, 93, pp. 291-302, 2016. http://dx.doi.org/10.1016/j.enpol.2016.03.016

[18] Assa, M.M., Maonga, B.B. \& Gebremariam, G.G., Non-price determinants of household's choice of cooking energy in Malawi. International Journal of Development and Sustainability, 4(1), pp. 18-28, 2015.

[19] Ekholm, T., Krey, V., Pachauri, S. \& Riahi, K., Determinants of household energy consumption in India. Energy Policy, 38(10), pp. 5696-5707, 2010. https://doi.org/10. 1016/j.enpol.2010.05.017

[20] Kwakwa, P.A., Wiafe, E.D. \& Alhassan, H., Households Energy Choice in Ghana. Journal of Empirical Economics, 1(3), pp. 96-103, 2013. 


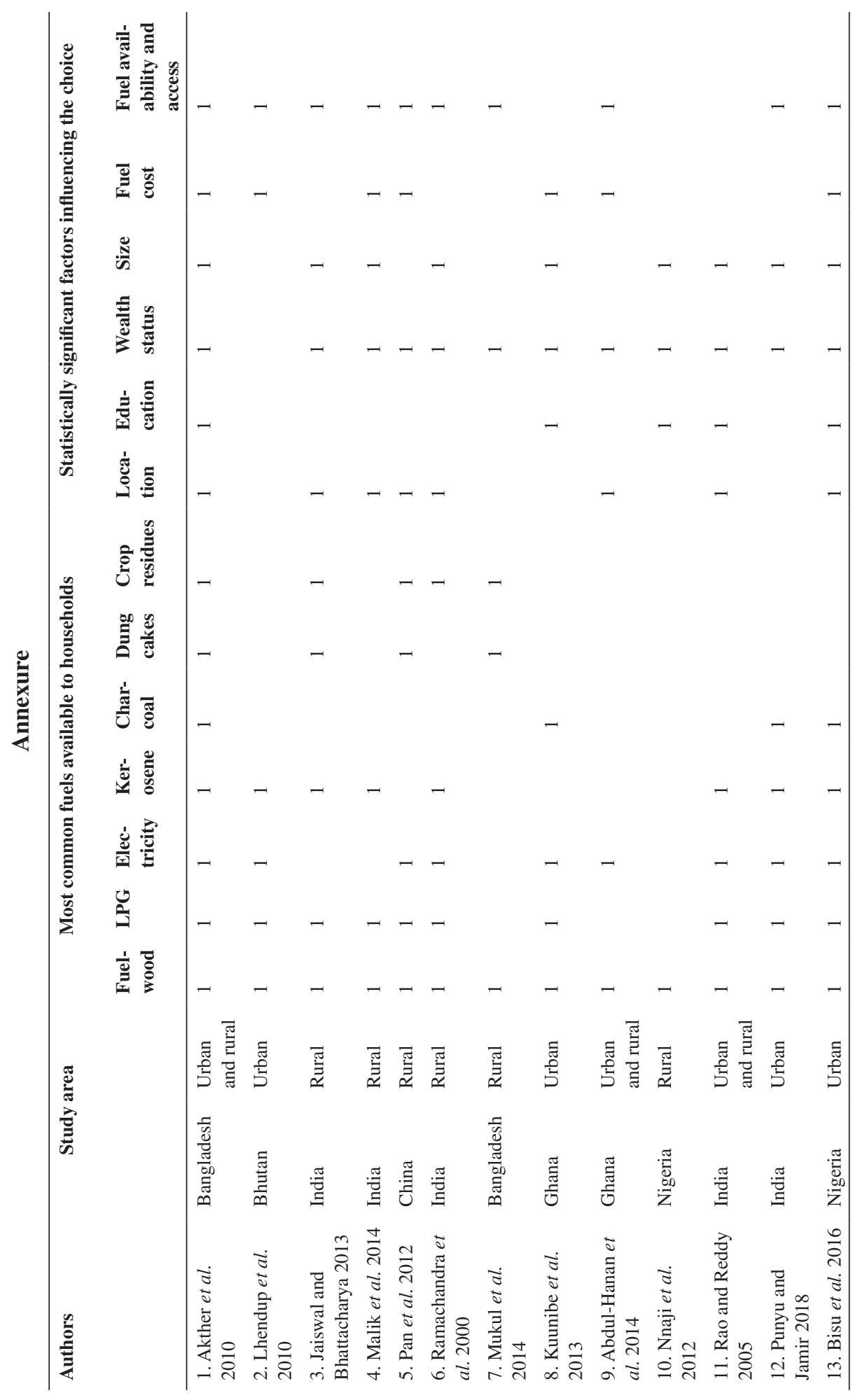




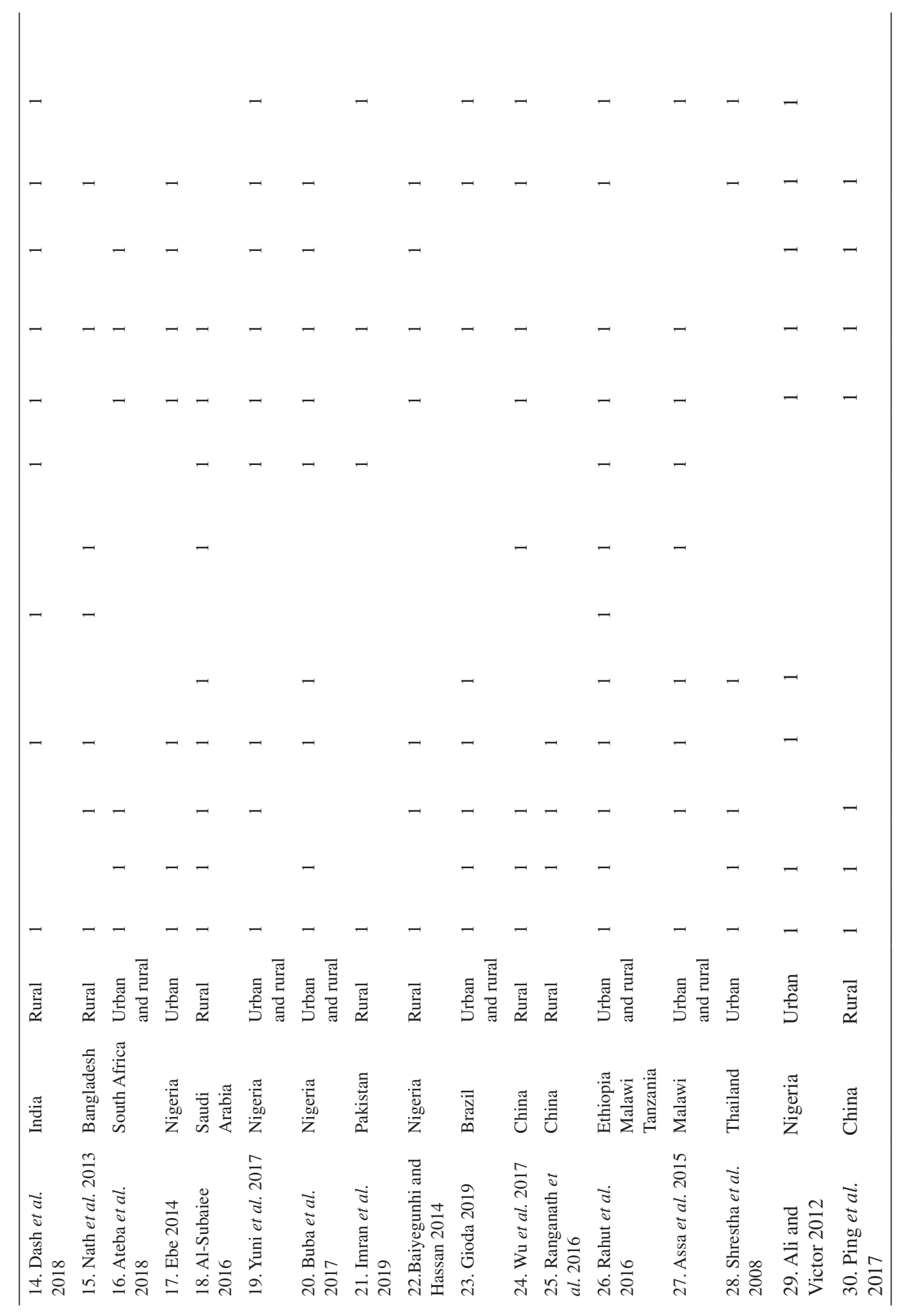




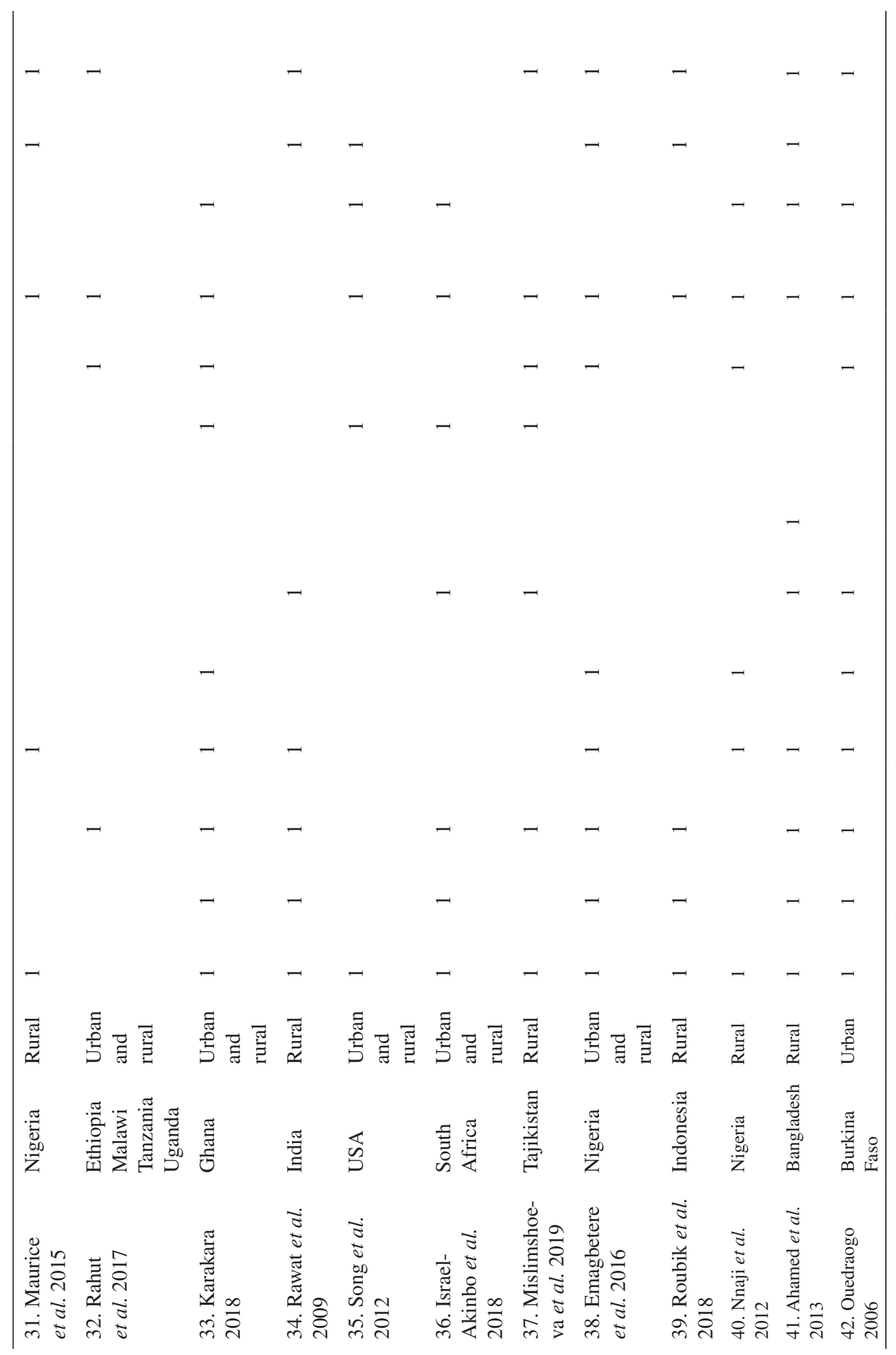




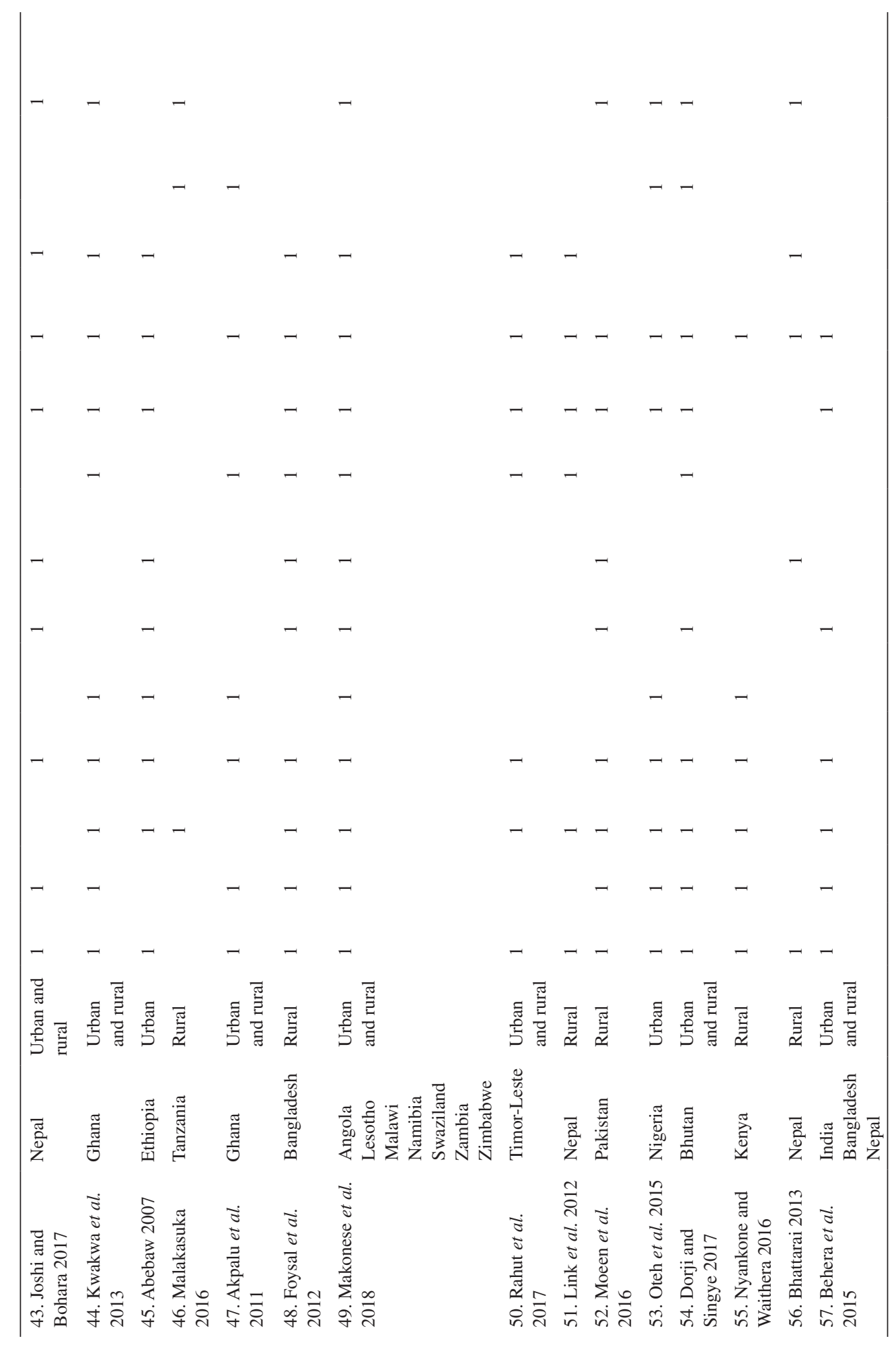




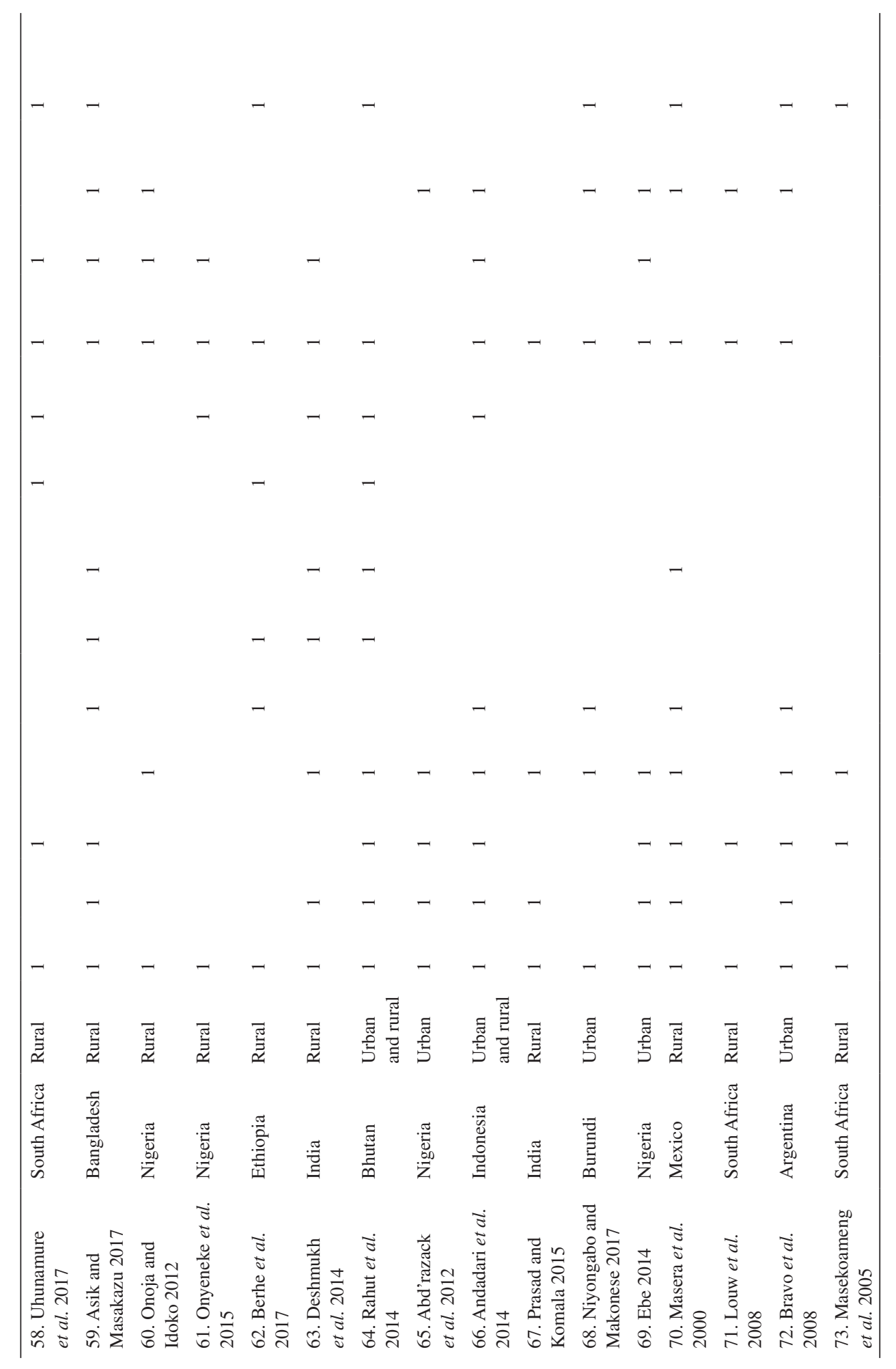




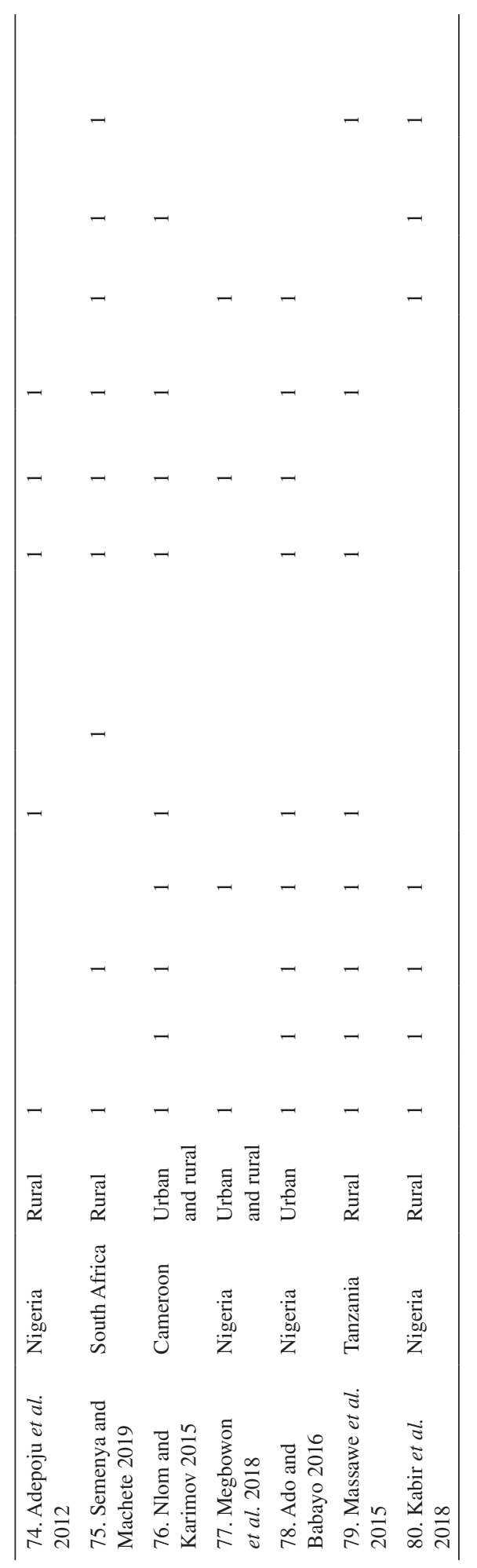

